\title{
Malignant pediatric intracerebral nerve sheath tumor in neurofibromatosis type 1
}

\author{
Seyyed Ali Nabavizadeh • Arastoo Vossough
}

Received: 10 December 2008/Published online: 7 March 2009

(C) Springer-Verlag 2009

\section{Dear Editor:}

We read with interest the article by Oztanir et al., published in Child's Nervous System, describing a supratentorial malignant intracerebral nerve sheath tumor (MINST) in a 14-month-old girl with neurofibromatosis type 1 (NF-1) [1]. We wanted to bring attention to some points in regard to this article about this very rare tumor.

The authors propose that MINST may have a propensity to be located infratentorially in adults and supratentorially in children and teenagers. However, three of the previous 11 reported cases of MINST (the authors had found six in their literature review) were located supratentorially in adults. De Cauwer et al. described a case of MINST in a 57year-old male in the right parietofrontal lobe [2]. Furthermore, there are two case reports of MINST of the lateral ventricles in 57- and 40-year-old patients [3, 4]. The authors also state that this is the first report of the occurrence of MINST in the context of NF-1. However, there are three previous cases of this association in the literature, in both adults and children [2, 3, 5], granted these three other cases with NF-1 association have been reported with the triton variant of MINST.

The imaging features of all previously described cases of MINST were nonspecific, mixed intensity-enhancing lesions, with presence of calcification in a minority of cases, features which did not allow differentiation from more commonly encountered tumors. However, there is a recent report on magnetic resonance spectroscopy (MRS) features in an intracerebral pontine malignant nerve sheath tumor in which Kozić et al. describe the presence of very high choline concentration associated with complete lack of creatine and NAA, suggesting the non-glial origin of the mass [6]. The actual usefulness of this finding in differentiating these tumors from other glial and non-glial tumors using MRS remains to be determined.

\section{References}

1. Oztanir N, Emmez H, Aytar MH, Dogan M, Kaymaz M, Baykaner MK (2009) Malignant intracerebral giant nerve sheath tumor in a 14-month-old girl with neurofibromatosis type 1: a case report. Childs Nerv Syst 25:253-256

2. De Cauwer H, Bogers JP, Duwel V, den Hauwe V, Croese P, Van Marck E (2007) An intracerebral intraparenchymatous triton tumor in a man with neurofibromatosis. J Neurol 254:1009-11

3. Takahashi Y, Sugita Y, Abe T, Yuge T, Tokutomi T, Shigemori M (2000) Intraventricular malignant triton tumor. Acta Neurochir (Wien) 142:473-476

4. Jung JM, Shin HJ, Chi JG, Park IS, Kim ES, Han JW (1995) Malignant intraventricular schwannoma. J Neurosurg 82:121-124

5. Bornstein-Quevedo L, Peralta-Olvera F, Marhx-Bracho A, Rodríguez-Jurado R, De Leon-Bojorge B (2003) Cerebral malignant nerve sheath tumor, triton tumor variant: case report. Pediatr Dev Pathol 6:168-72

6. Kozić D, Nagulić M, Samardzić M, Ostojić J, Rasulić L, Cvetković-Dozić D (2008) Intrapontine malignant nerve sheath tumor: MRI and MRS features. Acta Neurol Belg 108:67-71 